\title{
Hybrid Professionals and Academic Productivity: The Case of the University Polyclinic in Messina (Sicily)
}

\author{
Angela Alibrandi, Lara Gitto, Michele Limosani, Guido Noto \\ Dipartimento di Economia, Università degli Studi di Messina, Messina, Italy \\ Email: michele.limosani@unime.it, lara.gitto@unime.it
}

How to cite this paper: Alibrandi, A., Gitto, L., Limosani, M. and Noto, G. (2021) Hybrid Professionals and Academic Productivity: The Case of the University Polyclinic in Messina (Sicily). Health, 13, 1-15. https://doi.org/10.4236/health.2021.131001

Received: November 11, 2020

Accepted: January 5, 2021

Published: January 8, 2021

Copyright $\odot 2021$ by author(s) and Scientific Research Publishing Inc. This work is licensed under the Creative Commons Attribution International License (CC BY 4.0).

http://creativecommons.org/licenses/by/4.0/

\section{(c) (i) Open Access}

\begin{abstract}
The productivity of medical staff within a polyclinic is not an easy task due to the multiple activities that physicians must perform at the same time: not only healthcare for patients, but also academic activities, such as scientific research and teaching. Hybrid professionals are healthcare professionals who have to play multiple roles, often not precisely identified. This analysis examines the case study of the University Polyclinic of Messina (Italy) where three university departments and 7 Dipartimenti di Attività Integrate (DAI) are distinguished and physicians (both professors and researchers) are called to reconcile multiple tasks. Given the distinction between university departments and DAIs, the aim of this contribution is to identify the organizational elements that prove to be predictors of scientific efficiency and productivity. To what extent does the inclusion in a DAI or within a university department affect individual incentives? A new dataset is built for the present research containing information on University Polyclinic of Messina physicians (full professors, associate professors, researchers). From the Scopus online database (https://www.scopus.com/home.uri) individual information relating to the number of publications, the number of citations, h-index was obtained. The latter is used to assess the quality of individual research; in order to evaluate the teaching activity, the number of hours dedicated to didactical activities is taken into account, together with the number of teaching hours required by one's role. Information related to remuneration and the circumstance of carrying out intramural activities has also been included. A thorough statistical analysis is carried out and the individual groups (DAI and university departments) are compared through the Kruskal Wallis test. Estimating a Poisson Gamma mixture model highlights those variables that are significant predictors of scientific productivity. Attention paid to organizational methods should allow identifying the ideal setting for hybrid professionals to
\end{abstract}


practice the medical profession, while carrying out managerial duties, without compromising the quality of teaching and research. An efficient solution could thus be proposed to the complex multi-objective optimization problem that healthcare professionals are called to answer.

\section{Keywords}

Hybrid Professionals, University Departments, DAI, h-Index, Poisson-Gamma Mixture Model

\section{Introduction}

Public organizations carrying out "knowledge-intensive" activities have often been defined as "professional bureaucracies" [1], i.e. organizations relying on the skills and competencies of the working professionals. These organizations include public administrations operating in the fields of education, social services and health [2]. Since the New Public Management (NPM) reform, in the 1980s [3], the professionals involved in the provision of "knowledge-intensive" services were also called upon to fill functions and managerial responsibility [4]. This led to the development of the so-called "hybrid professionals", professional figures combining technical skills with administrative-managerial functions.

The Italian National Health Service (NHS) has implemented NPM-style reforms since the early $90 \mathrm{~s}$ of the last century. Following the legislative decree $\mathrm{n}$. $502 / 1992$, which introduced the so-called "second health reform" after the establishment of the NHS in 1978, the Aziende Sanitarie Locali (ASL) replaced the existing Local Health Units; the hospitals were structured according to a managerial model and were recognized as public legal personality holders. They are now to be meant as "hospital companies".

University Polyclinics are framed in this scenario. They are a particular type of hospital company (so-called "hospital-university company"), established with University Rectors' decrees. In this context, medical staff belonging to a University Hospital is called to carry out more than one task, concerning not only healthcare for patients, but research and university teaching activities as well: the obligation to accomplish academic tasks constitutes the distinction with respect to the activity envisaged by law for a physician employed in a hospital.

The assistance activities present levels of reciprocal and complex interdependence with research and teaching, which must be managed with adequate organizational strategies: the integration between healthcare-teaching-research assistance must be considered the real added value of the hospital-university company. However, at an operational level, critical aspects may emerge, due to the fact that the two institutions, hospital and university, maintain their specific regulatory, contractual and value characteristics [5].

As result, the search for organizational and management solutions oriented towards integration, which can safeguard the quality of assistance and teaching 
provided by the individual doctor, as well as innovation in research, is essential [6]. These solutions must be aimed at supporting the productivity of professionals, i.e. the ability to perform the activities required by their role together with the contribution requested by different institutional users (patients, Region, Ministry of Health, etc.).

Doctor's productivity has been examined by various studies, both in the specific medical contexts and at the individual level [7] [8] [9]. The productivity of medical staff within a polyclinic, however, is difficult to assess, precisely because of the multiple activities that must take place simultaneously. The present work explores such a possibility and aims at studying productivity and its determinants with reference to the doctors of a university hospital [10]. We will address, in particular, the following questions: Do organizational variables play a role in the scientific productivity of university physicians? What are the organizational variables that turn out to be predictors of academic productivity? To what extent membership in a university department may determine individual incentives for carrying out teaching and scientific research? Could the economic profile (in particular, the part of the remuneration-so-called "hospital integration"- relating to the care provided to patients or the remuneration paid for intramural care) have a fundamental role for productivity?

The analysis builds on a new database coming from University Hospital of Messina where three university departments and seven Integrated Activities Departments (Dipartimenti di Attività Integrate-DAIs) can be distinguished at an organizational level.

The work is organized as follows: after discussing the characteristics of the so-called "hybrid professionals", i.e. health professionals who have to perform several activities, we will present some descriptive statistics about the physicians of the University Hospital of Messina; finally, we will show estimation results and display some concluding remarks.

\section{The "Hybrid Professionals"}

Unlike "pure" professionals-who can be defined as individuals trained to carry out complex tasks independently and solve any problems through their experience and competence [11] - hybrid professionals combine professional activity with managerial responsibilities within the organization in which they operate [2] [12]. Healthcare professionals who work within healthcare companies are an example of hybrid professionals [2] [4] [13].

The hybridization process in healthcare, and the studies conducted so far, have mainly focused on the study of how the acquisition of managerial skills allows the use of governance tools by medical and healthcare personnel [13] [14] [15]. Some papers have examined, in particular, the resistance of health professionals to hybridization, perceived as a partial loss of their professional identity [13] [14], and to the evaluation of the impact on organizational performance management control tools, such as the budget [15]. 
Few studies, on the other hand, have focused on the implications in terms of productivity of healthcare personnel with managerial responsibilities. The issue of professional productivity has been widely explored in the literature, although with exclusive reference to specific tasks or activities [16], without considering the complexity of the role played by hybrid professionals.

The case study is of particular interest since the professional role of health care professionals and their managerial role in coordinating company resources added to the tasks of university teaching, research and technology transfer (so-called "third mission"). In the unique figure of the doctor of a University Polyclinic, the tasks normally performed by two or more professionals are brought together [17] [18] [19]. For this reason, it could be possible to talk about "super-hybrid" professionals.

In this perspective, it is clear how the triple objective of productivity-both academic, managerial, and welfare related, the latter known as the physicians's mission can be achieved by promoting suitable organizational methods to safeguard professionals' freedom to carry out their tasks.

\section{The Case Study}

The situation examined considers the University Hospital of Messina and data concern 291 physicians in the university role in 2018. These professionals are distinguished into full professors, associate professors and lecturers. At the time of data collection, together with physicians, there were 20 "type A" temporary researchers and 10 "type B" temporary researchers. An original dataset was used in the qualitative-quantitative analysis carried out; the dataset included information inferable from the university registry and relating to doctors pertaining to scientific areas 5 (=Biological Sciences) and 6 (=Medicine and Surgery).

The Messina University Hospital includes 3 university departments (see Table 1):

- "Biomedical, dental and biomorphic and functional imaging sciences", comprising 109 physicians;

- "Human pathology of adults and development age", which includes 108 doctors;

- "Clinical and experimental medicine", consisting of 74 doctors.

The male presence stands out, compared to the number of women, in particular, in the department of "human pathology of adults and development age" (31.5\%, vs. $36.5 \%$ and $36.7 \%$ in the other departments).

From the organizational-functional point of view there are, instead, 7 DAIs. DAIs, Dipartimenti di Attività Integrate (Integrated Activities Departments) are organizational structures, aimed at ensuring the integrated exercise of welfare, teaching and research activities.

Within each DAI, Complex Operating Units (Unità Operative ComplesseUOC) are identified. They have budget responsibility and operate, for their specific skills, in technical-professional and organizational management autonomy 
Table 1. Number and \% of physicians according to role and gender within each university department.

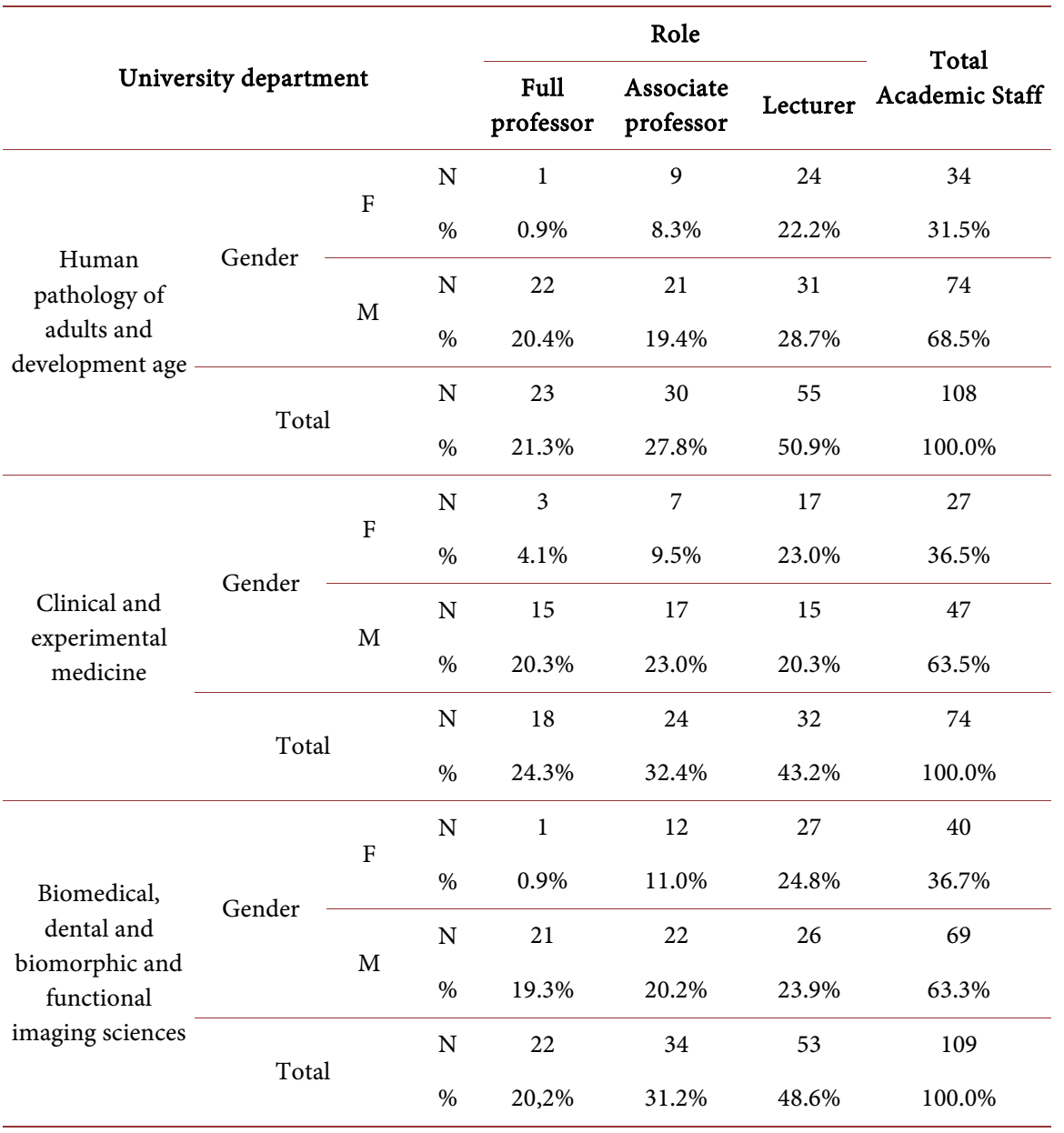

with full responsibility for the use of resources. Instead, Simple Operating Units (Unità Operative Semplici-UOS) have limited responsibility for the management of human, structural, technical and financial resources for the use of which each UOS is accountable to the Director of the corresponding UOC. The DAIs of the University Hospital of Messina and the composition of the university medical staff within each DAI, can be observed in Table 2 .

With regard to gender, the male presence is particularly pronounced in the DAI "Diagnostic Imaging" (84.6\%, of males, of which $38.5 \%$ full professors) or in the DAI "Surgery" (74.4\%), while women are more numerous than male colleagues in the DAI "Services" (56.8\%). Permanent researchers are present, to a greater extent, again in the DAI "Surgery" (58.1\%) and in the DAI "Specialized Medicine and Oncology" (53.6\%). Instead, associate professors are more frequent in the DAI "Internal Medicine". The DAI "Internal Medicine" sees also the highest percentage of female researchers $(38.1 \%$, vs. $14.1 \%$ of overall researchers).

Variables related to role and academic engagement are included in the dataset as dichotomous variables. The dichotomous variables also concern information 
Table 2. Number and \% of medical managers according to role and gender within each DAI.

\begin{tabular}{|c|c|c|c|c|c|c|c|}
\hline & \multirow[b]{2}{*}{ DAI } & & & \multicolumn{3}{|c|}{ Role } & \multirow{2}{*}{$\begin{array}{c}\text { Total } \\
\text { Academic Staf }\end{array}$} \\
\hline & & & & $\begin{array}{c}\text { Full } \\
\text { professor }\end{array}$ & $\begin{array}{l}\text { Associate } \\
\text { professor }\end{array}$ & Lecturer & \\
\hline \multirow{6}{*}{ SURGERY } & \multirow{4}{*}{ Gender } & \multirow{2}{*}{$\mathrm{F}$} & $\mathrm{N}$ & 0 & 1 & 10 & 11 \\
\hline & & & $\%$ & $0.0 \%$ & $2.3 \%$ & $23.3 \%$ & $25.6 \%$ \\
\hline & & \multirow{2}{*}{$\mathrm{M}$} & $\mathrm{N}$ & 5 & 12 & 15 & 32 \\
\hline & & & $\%$ & $11.6 \%$ & $27.9 \%$ & $34.9 \%$ & $74.4 \%$ \\
\hline & \multirow{2}{*}{\multicolumn{2}{|c|}{ Total }} & $\mathrm{N}$ & 5 & 13 & 25 & 43 \\
\hline & & & $\%$ & $11.6 \%$ & $30.2 \%$ & $58.1 \%$ & $100.0 \%$ \\
\hline \multirow{6}{*}{$\begin{array}{l}\text { DIAGNOSTIC } \\
\text { IMAGING }\end{array}$} & \multirow{4}{*}{ Gender } & \multirow{2}{*}{$\mathrm{F}$} & $\mathrm{N}$ & 0 & 1 & 1 & 2 \\
\hline & & & $\%$ & $0.0 \%$ & $7.7 \%$ & $7.7 \%$ & $15.4 \%$ \\
\hline & & \multirow{2}{*}{ M } & $\mathrm{N}$ & 5 & 2 & 4 & 11 \\
\hline & & & $\%$ & $38.5 \%$ & $15.4 \%$ & $30.8 \%$ & $84.6 \%$ \\
\hline & \multirow{2}{*}{\multicolumn{2}{|c|}{ Total }} & $\mathrm{N}$ & 5 & 3 & 5 & 13 \\
\hline & & & $\%$ & $38.5 \%$ & $23.1 \%$ & $38.5 \%$ & $100.0 \%$ \\
\hline \multirow{6}{*}{ EMERGENCIES } & \multirow{4}{*}{ Gender } & \multirow{2}{*}{$\mathrm{F}$} & $\mathrm{N}$ & 1 & 3 & 9 & 13 \\
\hline & & & $\%$ & $2.6 \%$ & $7.7 \%$ & $23.1 \%$ & $33.3 \%$ \\
\hline & & \multirow{2}{*}{ M } & $\mathrm{N}$ & 5 & 13 & 8 & 26 \\
\hline & & & $\%$ & $12.8 \%$ & $33.3 \%$ & $20.5 \%$ & $66.7 \%$ \\
\hline & \multirow{2}{*}{\multicolumn{2}{|c|}{ Total }} & $\mathrm{N}$ & 6 & 16 & 17 & 39 \\
\hline & & & $\%$ & $15.4 \%$ & $41.0 \%$ & $43.6 \%$ & $100.0 \%$ \\
\hline \multirow{6}{*}{$\begin{array}{l}\text { MATERNAL-PEDI } \\
\text { ATRICS }\end{array}$} & \multirow{4}{*}{ Gender } & \multirow{2}{*}{$\mathrm{F}$} & $\mathrm{N}$ & 0 & 3 & 6 & 9 \\
\hline & & & $\%$ & $0.0 \%$ & $13.6 \%$ & $27.3 \%$ & $40.9 \%$ \\
\hline & & \multirow{2}{*}{ M } & $\mathrm{N}$ & 5 & 3 & 5 & 13 \\
\hline & & & $\%$ & $22.7 \%$ & $13.6 \%$ & $22.7 \%$ & $59.1 \%$ \\
\hline & \multirow{2}{*}{\multicolumn{2}{|c|}{ Total }} & $\mathrm{N}$ & 5 & 6 & 11 & 22 \\
\hline & & & $\%$ & $22.7 \%$ & $27.3 \%$ & $50.0 \%$ & $100.0 \%$ \\
\hline \multirow{6}{*}{$\begin{array}{l}\text { INTERNAL } \\
\text { MEDICINE }\end{array}$} & \multirow{4}{*}{ Gender } & \multirow{2}{*}{$\mathrm{F}$} & $\mathrm{N}$ & 0 & 1 & 8 & 9 \\
\hline & & & $\%$ & $0.0 \%$ & $4.8 \%$ & $38.1 \%$ & $42.9 \%$ \\
\hline & & \multirow{2}{*}{ M } & $\mathrm{N}$ & 3 & 6 & 3 & 12 \\
\hline & & & $\%$ & $14.3 \%$ & $28.6 \%$ & $14.3 \%$ & $57.1 \%$ \\
\hline & $T_{0}$ & & $\mathrm{~N}$ & 3 & 7 & 11 & 21 \\
\hline & & & $\%$ & $14.3 \%$ & $33.3 \%$ & $52.4 \%$ & $100.0 \%$ \\
\hline & & $\Gamma$ & $\mathrm{N}$ & 1 & 2 & 3 & 6 \\
\hline SPECIALIZED & & $\Gamma$ & $\%$ & $3.6 \%$ & $7.1 \%$ & $10.7 \%$ & $21.4 \%$ \\
\hline ONCOLOGY & 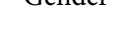 & $M$ & $\mathrm{~N}$ & 7 & 3 & 12 & 22 \\
\hline & & & $\%$ & $25.0 \%$ & $10.7 \%$ & $42.9 \%$ & $78.6 \%$ \\
\hline
\end{tabular}




\begin{tabular}{|c|c|c|c|c|c|c|c|}
\hline & \multirow{2}{*}{\multicolumn{2}{|c|}{ Total }} & $\mathrm{N}$ & 8 & 5 & & \\
\hline & & & $\%$ & $28.6 \%$ & $17.9 \%$ & $53.6 \%$ & $100.0 \%$ \\
\hline \multirow{6}{*}{ SERVICES } & \multirow{4}{*}{ Gender } & \multirow{2}{*}{$\mathrm{F}$} & $\mathrm{N}$ & 2 & 8 & 15 & 25 \\
\hline & & & $\%$ & $4.5 \%$ & $18.2 \%$ & $34.1 \%$ & $56.8 \%$ \\
\hline & & \multirow{2}{*}{ M } & $\mathrm{N}$ & 9 & 3 & 7 & 19 \\
\hline & & & $\%$ & $20.5 \%$ & $6.8 \%$ & $15.9 \%$ & $43.2 \%$ \\
\hline & \multirow{2}{*}{\multicolumn{2}{|c|}{ Total }} & $\mathrm{N}$ & 11 & 11 & 22 & 44 \\
\hline & & & $\%$ & $25.0 \%$ & $25.0 \%$ & $50.0 \%$ & $100.0 \%$ \\
\hline
\end{tabular}

on gender (male/female), age (over 50 years old/under 50), and the performance of managerial positions within the relevant DAI. In general, the average age of university doctors is 55 , and the majority $(70.4 \%)$ is over 50 .

In order to evaluate the teaching activity, the number of hours dedicated to this activity was taken into account, compared to the amount of teaching hours required by one's role. The teaching commitment required is not always completely carried out. In spite of a minimum of 60 teaching hours and a maximum of 120 teaching hours, depending on the role, the average is around 65, with a number of free hours compared to the required commitment which, in many cases, is higher than 100, up to the maximum value of almost 114 teaching hours. Individual information relating to the number of publications, the number of citations, h-index was obtained from the Scopus online database (https://www.scopus.com/), which are used to assess the quality of research [20].

Since the consolidation of academic career often takes place many years after the beginning of work, the university physician has to build his scientific reputation within the structure where he/she operates, collaborating with other professionals who become part of the team. After many years, the physician should have acquired greater scientific productivity, as well as higher quality of care provided, due to the longstanding experience.

A separate discussion must take place for the remuneration profile. The remuneration is, in fact, made up of various items: in addition to the university salary, paid on the basis of the academic role, there is a supplement for the hospital activity, fixed and variable parts relating to the position, to which salary and other fees are added, including carrying out intramural activities. Since the salary for academic activity is pre-defined at national level, it could be hypothesized that the economic incentive does not constitute a predictor of greater productivity for the healthcare professional engaged in the academic field, for which it is the performance resulting from the hospital activities and managerial duties that may determine an overall higher remuneration.

Rather, a greater commitment to academic research could be justified by the prestige that can be enjoyed by the health professional: a greater knowledge within an external environment could, in turn, justify an increase in the fees re- 
quired for privately rendered consultancy. Hence, the prestige, a factor not precisely defined, and referring to success in one's activity, translates into a greater probability of obtaining higher salaries, a higher stability in salaries and greater career opportunities [21].

In this context, the prestige will be able to guarantee a higher income, allowing the physicians to ask for higher compensation for both private and intramural activities; these factors, in turn, result in additional income. In the light of these considerations, it is therefore appropriate to assess whether there are limits to the possibility of carrying out an activity that is not strictly related to health care or academic research within the University Hospital, but which benefits from this in terms of prestige.

\section{Results}

The statistical analysis is carried out on a sample of 321 doctors from the University Hospital of Messina, who are framed in various university roles. In the light of the above considerations, attention was paid to the indicators of scientific productivity (number of scientific publications, number of citations and h-index), of teaching (ratio between the number of hours of teaching provided compared to the expected commitment, on the basis of the academic role covered) and, finally, on the total remuneration.

First of all, a comparison was carried out to verify if there is a significant differentiation between the seven DAIs and between the three university departments. The Kruskal Wallis non-parametric test was used, since it allows a comparison between independent samples, without assuming a specific distribution of the variables or, in any case, for numerical variables distributed in a nonnormal way [22].

Table 3 reports the mean and standard deviation of the indicators of academic activity examined, according to the different DAIs and to the university departments. The p-values refer to the comparison made using the Kruskal Wallis test; statistically significant p-values are highlighted in bold, at the significance level of 0.050 .

The results reveal considerable differences between the DAIs: in particular, the DAI Surgery is characterized by the lowest values of the research parameters, a circumstance that can be explained by considering the need and the priority deriving from surgical interventions and the management of the operating room, which significantly reduces the time to devote to scientific research. The DAI Surgery is also characterized by a higher average salary. Physicians belonging to the DAI Internal Medicine appear to be the most scientifically active and the most engaged in teaching as well: their effective teaching/expected teaching ratio is significantly higher than the other DAIs. On the other hand, the DAI Diagnostics Imaging differs significantly from the others departments because of the lower value of their effective teaching/expected teaching ratio. Comparing the three university departments, it is possible to observe higher average 
Table 3. Mean and standard deviation of academic activity indicators according to DAI.

\begin{tabular}{|c|c|c|c|c|c|}
\hline DAI & H-INDEX & $\begin{array}{l}\text { Number of } \\
\text { publications }\end{array}$ & $\begin{array}{l}\text { Number of } \\
\text { citations }\end{array}$ & $\begin{array}{c}\text { Teaching activity } \\
\text { (taught hours/expected } \\
\text { teaching activity) }\end{array}$ & $\begin{array}{c}\text { Remuneration } \\
\text { (thousands of } \\
€ \text { ) }\end{array}$ \\
\hline & \multicolumn{5}{|c|}{ Comparison among DAIs } \\
\hline SURGERY & $8.7 \pm 5.5$ & $43.9 \pm 32.7$ & $389.8 \pm 457.7$ & $0.62 \pm 0.39$ & $114.9 \pm 128$ \\
\hline DIAGNOSTIC IMAGING & $17.6 \pm 7.5$ & $91.0 \pm 52.3$ & $1049 \pm 758.6$ & $0.39 \pm 0.31$ & $110.8 \pm 39.3$ \\
\hline EMERGENCIES & $16.7 \pm 9.4$ & $87.3 \pm 60.8$ & $1346 \pm 1411.2$ & $0.62 \pm 0.30$ & $109.9 \pm 30.8$ \\
\hline MATERNAL-PEDIATRICS & $17.6 \pm 8.7$ & $78.4 \pm 50.3$ & $1582.2 \pm 1214.9$ & $0.55 \pm 0.31$ & $103.3 \pm 18.9$ \\
\hline INTERNAL MEDICINE & $19.7 \pm 12.1$ & $72.8 \pm 58.6$ & $2119.4 \pm 2802.8$ & $0.92 \pm 0.18$ & $97.7 \pm 23.2$ \\
\hline SPECIALIZED MEDICINE AND ONCOLOGY & $17.3 \pm 8.8$ & $101.3 \pm 81.0$ & $1525.1 \pm 1573.6$ & $0.55 \pm 0.35$ & $103.5 \pm 26.7$ \\
\hline SERVICES & $18.8 \pm 13.2$ & $74.8 \pm 79.9$ & $1522.7 \pm 2471.2$ & $0.86 \pm 0.22$ & $91.1 \pm 25.4$ \\
\hline P-Value & 0.000 & 0.003 & 0.000 & 0.000 & 0.009 \\
\hline University Department & \multicolumn{5}{|c|}{ Comparison among university departments } \\
\hline Human pathology of adults and development age & $13.3 \pm 9.1$ & $67.4 \pm 58.6$ & $1154.2 \pm 1441.3$ & $0.57 \pm 0.36$ & $112.4 \pm 94.4$ \\
\hline Clinical and Experimental Medicine & $21.5 \pm 13.1$ & $113.7 \pm 97.2$ & $2316.3 \pm 2521.8$ & $0.79 \pm 0.26$ & $104.6 \pm 26.5$ \\
\hline $\begin{array}{l}\text { Biomedical, dental and biomorphic and } \\
\text { functional imaging sciences }\end{array}$ & $15.0 \pm 10.0$ & $70.4 \pm 81.8$ & $1151.9 \pm 1739.4$ & $0.75 \pm 0.34$ & $94.9 \pm 29.1$ \\
\hline P-Value & 0.000 & 0.002 & 0.000 & 0.000 & 0.028 \\
\hline
\end{tabular}

values with respect to the indicators of scientific productivity for the Department of Clinical and Experimental Medicine. A similarity condition is found, however, between the other two departments. A subsequent phase of the analysis has identified which variables, among those ones examined, can be considered significant predictors of scientific productivity, in particular h-index, given that this indicator incorporates the number of scientific publications and takes into account the number of citations and impact factor [20]. As can be seen from Figure 1 , the h-index variable is discrete, non-negative and characterized by positive asymmetry.

h-index shows a trend similar to a "Poisson-Gamma mixture" distribution. The latter is a probability distribution associated with a Poissonian random variable, Poiss $(\lambda)$, in which the parameter $\lambda$ is not constant but varies like a Gamma random variable; this Poisson mixture loosens the very restrictive hypothesis that the variance is equal to the mean. In particular, it is assumed that the variance is always greater than the expected value and this assumption allows a more sophisticated and precise statistical approach for the analysis [23].

Keeping in mind these considerations, the next step of the analysis estimate a Poisson-Gamma regression [23] [24] [25] to model the relationship between $\mathrm{h}$-index and a set of independent variables. Among the possible predictors of scientific productivity, the explanatory power of the following variables regarding the h-index variable, which is assumed as a dependent variable, was tested:

- the circumstance of being full or associate professor with respect to the role of researcher; 


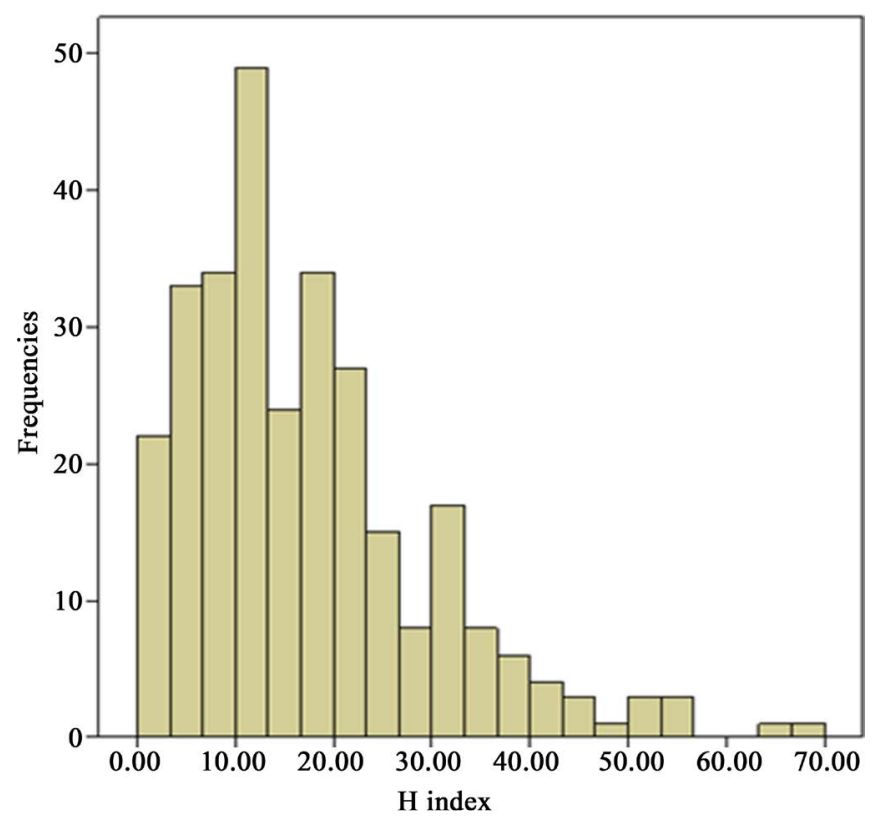

Figure 1. h-index distribution.

- the male gender;

- age over or equal to 50 years;

- the effect of the interaction between the circumstance of carrying out the role of manager within the Polyclinic, and the affiliation to the DAI Diagnostics Imaging, Emergencies, Maternal and Pediatrics, Internal Medicine, Specialized Medicine and oncology, Services, compared to the affiliation to the DAI Surgery, which is taken as a reference);

- affiliation, from an academic point of view, to the University Department of Biomedical, Dental and Morphological and Functional Imaging Sciences or to the University Department of Clinical and Experimental Medicine, with respect to the Department of Human Pathology of adults and of developmental age, which is taken as a reference;

- the hours of teaching activity compared to the hours expected by the academic role;

- the total remuneration.

The results of the model, in which the link function used is the logarithm and the estimates were obtained by the MLE (Maximum Likelihood Estimation) method, can be observed in Table 4.

It emerges the significance of numerous predictors of scientific productivity. In particular, being full or associate professor increases the probability of registering a higher h-index. The male gender and the younger age group have a positive and significant effect in bringing about greater productivity.

It is interesting to evaluate the affiliation to the different DAI, assessed together with the circumstance of being a medical manager: the variables that consider this interaction are all significant for the units in the sample, comparing to DAI Surgery, which is taken as a reference. Instead, considering the affiliation to 
Table 4. Mixture Poisson-Gamma model.

\begin{tabular}{|c|c|c|c|}
\hline Variable & Coefficient & $\begin{array}{c}\text { Confidence } \\
\text { interval } 95 \%\end{array}$ & P-value \\
\hline Intercept & 2.249 & $2.015 ; 2.484$ & $<0.001$ \\
\hline Full professor & 0.768 & $0.649 ; 0.887$ & $<0.001$ \\
\hline Associate Professor & 0.405 & $0.311 ; 0.500$ & $<0.001$ \\
\hline Gender (M) & 0.109 & $0.022 ; 0.196$ & 0.014 \\
\hline Age ( $>50$ years) & -0.313 & $-0.403 ;-0.222$ & $<0.001$ \\
\hline Manager ${ }^{\star}$ DAI Diagnostic imaging & 0.290 & $0.039 ; 0.541$ & 0.024 \\
\hline Manager ${ }^{*}$ DAI Emergencies & 0.392 & $0.207 ; 0.577$ & 0.022 \\
\hline Manager * DAI Maternal-pediatrics & 0.751 & $0.554 ; 0.948$ & $<0.001$ \\
\hline Manager ${ }^{\star}$ DAI Internal Medicine & 0.437 & $0.217 ; 0.656$ & $<0.001$ \\
\hline Manager * DAI Specialized medicine and oncology & 0.406 & $0.200 ; 0.612$ & 0.004 \\
\hline Manager ${ }^{\star}$ DAI Services & 0.540 & $0.368 ; 0.712$ & 0.001 \\
\hline $\begin{array}{l}\text { Department of Biomedical, Dental and } \\
\text { Morphological and Functional Imaging Sciences }\end{array}$ & 0.031 & $-0.082 ; 0.144$ & 0.591 \\
\hline Department of Clinical and experimental medicine & 0.395 & $0.281 ; 0.509$ & $<0.001$ \\
\hline Teaching hours/expected hours & 0.052 & $-0.081 ; 0.188$ & 0.451 \\
\hline Total remuneration & -0.001 & $-0.002 ; 0.000$ & 0.254 \\
\hline
\end{tabular}

the various university departments, the only significance of the Department of Clinical and Experimental Medicine can be highlighted, compared to the Department of Adult Human Pathology and Developmental Age, taken as a reference. Finally, neither the teaching provided nor the remuneration was significant in determining the probability of achieving a higher h-index.

From a strictly methodological point of view, the estimated model was checked using the deviance test, calculated as the difference between the log- likelihood of the estimated model and that of the saturated model (i.e. the model having a number of parameters equal to the size of the sample). The resulting non- significance $(\mathrm{p}=0.871)$ demonstrates that there are no significant differences between the observed values and the theoretical ones obtained from the estimate of the statistical model.

Finally, a graphic analysis of the residues was carried out to highlight systematic deviations between observed and estimated values: both the graphical and analytical approaches, to verify the goodness of fit, confirm the adequacy of the estimated model.

\section{Concluding Remarks}

This paper focuses on the main activities carried out by super-hybrid professionals at the University Hospital of Messina (Sicily) and estimates the effects of such multiple and often conflicting activity on their productivity. Overall, the empirical analysis shows how hybrid professionals are influenced by the aca- 
demic affiliation and the circumstance to perform managerial activities, and respond to incentives deriving by economic remuneration.

In particular, we have seen how the DAIs physicians belong to, therefore the organizational-managerial context, is one of the main determinants of productivity, both related to scientific and learning activities. This result can be explained by three distinct reasons, which, however, are not mutually exclusive. One reason is related to the type of assistance activity conducted within the DAI. Considering that, within each DAI a homogeneous and predictable type of care takes place, it is possible to believe that the circumstance of returning to some of these departments (for example, DAI Surgery) and providing assistance activities, requires professionals to spend a longer time with the aim to consolidate their expertise. Another reason could be related to the different organizational cultures that characterize the different DAIs [26]: for example, it is possible that, within some DAIs, research and/or teaching are more relevant comparing to other activities. A final reason, exclusively referable to scientific research, relates to the editorial position of the journals for each scientific sector. In fact, the reference journals of each scientific sector are different: consequently, the average impact factors and the average number of citations can change considerably, in spite of the same number of scientific publications.

Empirical analysis, furthermore, suggests how higher h-indexes correspond to higher academic roles (for example, full professors vs. lecturers). This evidence is explained by the time delay with which the citations of each scientific article occur. The average time of publication of a scientific article can vary between one and two years: consequently, an article published in 2020 will begin to have an effective response in terms of citations no earlier than 2021-2022. It is clear, therefore, how full professors, who have been publishing for several years, benefit most from this dynamic.

The analysis displays, moreover, intriguing results in terms of the number of publications with reference to the physicians' age and gender. The greater productivity in terms of the number of publications by younger people can be explained by their motivation, aimed at increasing their professional reputation, progressing in academic career. Concerning gender, professors and lecturers seem to be more productive than their female colleagues. This aspect could be linked to the gender gap existing between the actual possibilities of the development of academic careers, not only in Italy but also in other countries [27] [28]. Young women often find themselves too busy with the tasks to manage family which, inevitably, takes them away from professional activity and research [29]. This interpretation is confirmed by numerous contributions on the topic and in the University balance documents, reporting the level of remuneration for male and female physicians [30]. The conclusions reached, therefore, confirm what has already stressed by the relevant literature: the formulation of ad hoc policies to encourage the scientific productivity of subjects who hold greater personal and family responsibilities should be strengthened [31]. 
Finally, the significance of the coefficients associated with the variables that consider the interaction between the performance of managerial tasks and the affiliation to different DAIs, confirms that a multitasking role is not a factor that precludes the possibility of carrying out successfully academic activities. Indeed, the acquisition of greater skills in several areas is a factor that significantly increases the scientific productivity of physicians and allows them to take care of patients, both in hospitals and in the exerting intramural or private activities.

Last but not least, the non-significance of the coefficient associated with the total remuneration could be interpreted in the sense of irrelevance of this variable with respect to other physicians' objectives. In spite of higher remuneration, university doctors show greater interest in strengthening their skills, and in performing multiple activities, including the academic tasks, from which they may acquire recognition, prestige and, in the end, the possibility of higher remuneration.

An aspect to be investigated and evaluated jointly with academic (university teaching and scientific research) and managerial productivity, will concern the satisfaction expressed by patients and the consequences in terms of outcome for potential users. These preliminary results are likely to influence the work planning of health professionals, which should take into account the academic (i.e. belonging to university departments) and managerial (belonging to DAI) positions of the professionals.

\section{Conflicts of Interest}

The authors declare no conflicts of interest regarding the publication of this paper.

\section{References}

[1] Mintzberg, H. (1989) The Structuring of Organizations. In: Asch, D. and Bowman, C., Eds., Readings in Strategic Management, Palgrave, London, 322-352.

[2] Noordegraaf, M. (2007) From "Pure" to "Hybrid" Professionalism: Present-Day Professionalism in Ambiguous Public Domains. Administration \& Society, 39, 761 785. https://doi.org/10.1177/0095399707304434

[3] Hood, C. (1991) A Public Management for All Seasons? Public Administration, 69, 3-19. https://doi.org/10.1111/j.1467-9299.1991.tb00779.x

[4] Giacomelli, G. (2020) The Role of Hybrid Professionals in the Public Sector: A Review and Research Synthesis. Public Management Review, 20, 1624-1651. https://doi.org/10.1080/14719037.2019.1642952

[5] Leardini, C., Sala, G.A. and Campedelli, B. (2015) L'azienda ospedaliera universitaria integrata. Un modello di integrazione tra attività di cura, ricerca e formazione. Franco Angeli Editore.

[6] Ministero della Salute (2011) Integrazione Assistenza-Didattica-Ricerca: opportunità e vincoli per il Servizio Sanitario Nazionale e per l'Università. Materiali del network delle Aziende Ospedaliero Universitarie Italiane 2008-2010. http://wpuww.salute.gov.it/imgs/C_17_pubblicazioni_1518_allegato.pdf

[7] Storfa, A.H. and Wilson, M.L. (2015) Physician Productivity: Issues and Controver- 
sies. American Journal of Clinical Pathology, 143, 6-9. https://doi.org/10.1309/AJCP5M1FAMLCYNPX

[8] Rumbold, B.E., Smith, J.A., Hurst, J., Charlesworth, A. and Clarke, A. (2015) Improving Productive Efficiency in Hospitals: Findings from a Review of the International Evidence. Health Economics, Policy and Law, 10, 21-43. https://doi.org/10.1017/S174413311400022X

[9] Johannessen, K.A., Kittelsen, S.A. and Hagen, T.P. (2017) Assessing Physician Productivity Following Norwegian Hospital Reform: A Panel and Data Envelopment Analysis. Social Science \& Medicine, 175, 117-126. https://doi.org/10.1016/j.socscimed.2017.01.008

[10] Alibrandi, A., Gitto, L. and Limosani, M. (2020) Il medico universitario: Il bilanciamento tra attività accademiche e assistenziali. L'esperienza del Policlinico Universitario di Messina, Politiche Sanitarie, in Press.

[11] Derber, C. and Schwartz, W.A. (1991) New Mandarins or New Proletariat? Professional Power at Work. In: Research in the Sociology of Organizations, JAI Press, Greenwich, 71-96.

[12] Fitzgerald, L. and Ferlie, E. (2000) Professionals: Back to the Future? Human Relations, 53, 713-739. https://doi.org/10.1177/0018726700535005

[13] Kurunmäki, L. (2004) A Hybrid Profession-The Acquisition of Management Accounting Expertise by Medical Professionals. Accounting, Organizations and Society, 29, 327-347. https://doi.org/10.1016/S0361-3682(02)00069-7

[14] McGivern, G., Currie, G., Ferlie, E., Fitzgerald, L. and Waring, J. (2015) Hybrid Manager-Professionals' Identity Work: The Maintenance and Hybridization of Medical Professionalism in Managerial Contexts. Public Administration, 93, 412-432. https://doi.org/10.1111/padm.12119

[15] Macinati, M.S. and Rizzo, M.G. (2016) Exploring the Link between Clinical Managers Involvement in Budgeting and Performance: Insights from the Italian Public Health Care Sector. Health Care Management Review, 41, 213-223. https://doi.org/10.1097/HMR.0000000000000071

[16] Duszak Jr., R. and Muroff, L.R. (2010) Measuring and Managing Radiologist Productivity, Part 1: Clinical Metrics and Benchmarks. Journal of the American College of Radiology, 7, 452-458. https://doi.org/10.1016/j.jacr.2010.01.026

[17] Papanikolaou, P.N., Christidi, G.D. and Ioannidis, J.P.A. (2006) Patient Outcomes with Teaching versus Nonteaching Healthcare: A Systematic Review. PLoS Medicine, 3, e341. https://doi.org/10.1371/journal.pmed.0030341

[18] El Ouardighi, F., Kogan, K. and Vranceanu, R. (2009) Publish or Teach? Analysis of the Professor's Optimal Career Path. Journal of Economic Dynamics and Control, 37, 1995-2009. https://doi.org/10.1016/j.jedc.2013.05.007

[19] Tijdink, J.K. (2017) Publish \& Perish; Research on Research and Researchers. Tijdschrift voor Psychiatrie, 59, 406-413.

[20] Piazzini, T. (2010) Gli indicatori bibliometrici: Riflessioni sparse per un uso attento e consapevole. Italian Journal of Library, Archives, and Information Science, 1, 63-86.

[21] Freidson, E. (2002) La dominanza medica. Le basi sociali della malattia e delle istituzioni sanitarie. Franco Angeli Editore.

[22] McKight, P.E. and Najab, J. (2010) Kruskal-Wallis Test. The Corsini Encyclopedia of Psychology, 1, 1-10. https://doi.org/10.1002/9780470479216.corpsy0491

[23] Buchak, K. and Sakhno, L. (2017) Compositions of Poisson and Gamma Processes. 
Modern Stochastics. Theory and Applications, 4, 161-188. https://doi.org/10.15559/17-VMSTA79

[24] Jones, A. (2013) Modelli per dati di conteggio. In: Jones, A., Rice, N., Bago d'Uva, T. and Balia, S., Eds., Applied Health Economics, Routledge, London, 7-25.

[25] Minois, N., Savy, S., Lauwers-Cances, V., Andrieu, S. and Savy, N. (2017) How to Deal with the Poisson-Gamma Model to Forecast Patients' Recruitment in Clinical Trials When There Are Pauses in Recruitment Dynamic? Contemporary Clinical Trials Communications, 5, 144-152. https://doi.org/10.1016/j.conctc.2017.01.003

[26] Flamholtz, E.G., Das, T.K. and Tsui, A.S. (1985) Toward an Integrative Framework of Organizational Control. Accounting, Organizations and Society, 10, 35-50. https://doi.org/10.1016/0361-3682(85)90030-3

[27] Pulejo, L. (2012) La gender equality nell'economia dell'azienda. Strategie e strumenti di mainstreaming di genere per lo sviluppo sostenibile. FrancoAngeli.

[28] Pulejo, L. (2013) Il "bilancio di genere": Uno strumento di analisi e di programmazione per le Università nell'ottica della strategia di gender mainstreaming. Annali della Facoltà di Economia, Università degli Studi di Messina, 3, 119-130.

[29] Ronchetti, N. (2019) Donne e gender gap: Più brave all'università ma penalizzate su occupazione e retribuzione.

https://www.ilsole24ore.com/art/donne-e-gender-gap-piu-brave-all-universita-mapenalizzate-occupazione-e-retribuzione- $\mathrm{ABmv0 \textrm {PbB }}$

[30] Addabbo, T., Pulejo, L., Tomasin, P. and Tomio, P. (2018) Linee guida per il Bilancio di genere nelle Università. Presentazione alla CRUI-Gruppo sulle tematiche di genere Roma, 4 luglio 2018.

http://www.cpouniversita.it/documenti/Linee/linee_guida.pdf

[31] Abbiati, G. and Minello, A. (2019) Università, le donne devono scegliere tra maternità e carriera. Quattro azioni per colmare il gap di genere.

https://www.ilfattoquotidiano.it/2019/09/30/universita-le-donne-devono-scegliere-t ra-maternita-e-carriera-quattro-azioni-per-colmare-il-gap-di-genere/5472084/ 